\title{
CONFLITO SOCIOAMBIENTAL E POLUIÇÃO INDUSTRIAL: O CASO DA BACIA DO RIO GRAMAME-MUMBABA - PB
}

NUNES, Edilon Mendes. Professor a djunto das Faculdades ASPER e FASER. Doutorando em Desenvolvimento e Meio Ambiente - PRODEMA - Universidade Federal da Pernambuco. Mestre em Desenvolvimento e Meio Ambiente - PRODEMA - Universidade Federal da Paraíba. Graduado em Administração de Empresas e Ciências Sociais. João Pessoa-Paraíba. E-mail: edilonmendes@yahoo.com.br.

GARCIA, Loreley Gomes. Professora e coordenadora do Programa de Pós-graduação em Sociologia -

PPGS - Universidade Federal da Paraíba. Pós-doutora pela Southern Oregan University. Professora do

Programa de Pós-graduação em Desenvolvimento e Meio Ambiente - PRODEMA-UFPB.

E-mail: loreleygg@gmail.com.

\section{Resumo}

Este é um estudo de Ecologia Política. Trata-se da análise do Conflito Socioambiental de poluição industrial na Bacia do Rio Gramame, na comunidade de Mumbaba de Baixo, iniciado na década de 1960, mas que só muito recentemente passou a ser entendido como tal. Como se buscou compreender a complexidade do objeto em estudo, traçamos um caminho metodológico de análise do conflito a partir das partes que o compõem. Dessa forma, identificamos os atores, suas atuações, articulações, poderes e influência no conflito. Utilizamos uma metodologia socioantropológica por meio da observação participante, técnica "bola de neve", realização de entrevistas semiestruturadas, modelos mentais, análise de percepções e registros fotográficos. Constatamos que os atores não estão articulados e, em sua maioria, não desempenham seu papel definido por legislação, o que compromete as perspectivas de resolução, fazendo com que a situação se perpetue. Este trabalho se torna relevante por trazer à tona vozes que são silenciadas e, por isso, é um trabalho provocativo.

Palavras-chave: Ecologia política; Conflito socioambiental; Bacia do Rio Gramame; Mumbaba.

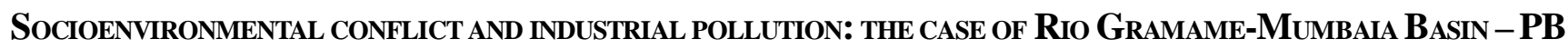

\begin{abstract}
This is a case study of Political Ecology. It is an analysis of the Social Environmental Conflict of industrial pollution in the Basin of Rio Gramame, in the community of Mumbaba de Baixo. Although this conflict has begun in the decade of 1960, it has been recognized only recently. As we have sought to understand the complexities of this study, we draw a methodological road of analysis of the conflict based on each part of its components. In this way, we have identified all those involved, their actions, articulations, powers, and their influence on the conflict. We have used a social-anthropological approach by means of participant observation, with the "snowball" technique, as well as semi-structured interviews, mental models, analysis of perceptions and photographic records. We have found that actors are not articulated and the majority of them do not follow their script as defined by legislation, which impairs the perspectives of resolution and, as a result, the situation has been perpetuated. This study is relevant for bringing to surface all the voices that go unheard, and for this reason, it is a provocative work.
\end{abstract}

KEYwORDS: Political Ecology; Social Environmental Conflict; Rio Gramame Basin; Mumbaba. 


\section{INTRODUÇÃO}

O movimento da Ecologia Política, surgido na década de 1980 através dos movimentos sociais e ambientalistas, possui um conceito basilar: Injustiça Ambiental. Injustiça dos ricos sobre os pobres, dos que possuem maior poder aquisitivo, poder e influência sobre os desprovidos. Injustiça no sentido de que o que é ruim é dividido entre todos (muito embora os maiores impactados sejam os pobres) e o que é bom, resultante, é aproveitado apenas por uma pequena parcela (ACSELRAD; MELO E BEZERRA, 2009).

Nessa perspectiva, a discussão acerca da distribuição e percepção de riscos é feita por Beck (2007, p. 96), quando o sociólogo alemão denomina a moderna sociedade de Sociedade de Risco e afirma, claramente, que a poluição é democrática. Nesta sociedade, a justiça ambiental e as éticas do meio ambiente são simplesmente sobrepostas pela sujeira ambiental, sob o argumento da ciência, do progresso, do desenvolvimento das grandes corporações que, além de prejudicarem todo o ecossistema, mantêm-se lucrando através de sua utilização. Com a destruição da qualidade de vida dos ecossistemas, crescem as limitações de seu uso pelas populações que desempenhavam uma relação de interdependência ou que utilizavam os recursos naturais do meio.

Nos Estados Unidos, anos 1980, surgiram movimentos populares contra a poluição, sobretudo porque, dentre outros motivos, percebeu-se que os negros, naquele país, eram submetidos a condições desiguais. O lixo tóxico e os rejeitos das indústrias eram lançados nos considerados "bairros negros". Além disso, o movimento (Racismo Ambiental) surgiu com o intuito de criticar as soluções tecnicistas aos problemas que deveriam ser discutidos e decididos por todos. Daí surgiu a ideia de Justiça Ambiental como conceito norteador da luta pela igualdade na qualidade do uso dos recursos, do meio ambiente em geral (Acselrad, Melo e Bezerra, 2009).

Dentre os princípios da Justiça Ambiental, constam "Poluição tóxica para ninguém", "Por uma transição justa" (a luta contra a poluição não pode destruir o emprego dos trabalhadores das indústrias ou penalizar as populações mais pobres, através da transferência do problema de um lugar para o outro). Portanto, o movimento de Justiça Ambiental não apregoa que o beneficiamento dos ricos se realize em detrimento da expropriação do uso dos recursos pelos pobres.

Por outro lado, Alier (2007) lembra que não existe civilização ecologicamente inocente. A população local contribui para a degradação do meio no qual está inserida, embora em nível, intensidade e forma diferente.

Em se tratando de conflitos, Little (2001, p.107), afirma que existem vários tipos e que estes estão em todas as esferas da vida humana, desde as esferas psicológicas, políticas, econômicas e religiosas. No entanto, os tipos de conflitos que mais têm se destacado, nos últimos anos, são os conflitos socioambientais denominados como "Conflitos Sociais Ambientalizados" (LOPES, 2006, p.34).

Existem conflitos em todas as esferas, por todas as causas. Aos conflitos são adicionadas variáveis como novas formas de lidar, novas estratégias e até novos atores, como o ambiente que não deve ser considerado apenas como palco da situação, mas como um agente de transformação capaz de modificar e de ser modificado pelos outros atores.

É nesse contexto que é inserida, na esfera dos conflitos, a esfera ambiental. Os Conflitos Socioambientais são aqueles nos quais os atores passam a utilizar a questão ambiental como repertório de seus interesses e reivindicações. Seriam, então, uma nova questão social, uma nova questão da esfera pública iniciada nos países industrializados, ligada aos grandes acidentes industriais, de seus riscos e de sua internacionalização (LOPES, 2006, p.34).

Com o intuito de não apenas listar, mas de conferir visibilidade, o Mapa de Conflitos envolvendo Injustiça Ambiental e Saúde no Brasil (2010) registrou cerca de 300 casos, em todos os estados do país. A lista não apresenta todos os conflitos existentes, como no caso da Paraíba, de que constam apenas seis: Fazendeiros versus Agricultores (Pocinhos); problemas causados por barragem (Alagoa Grande); relocação de ribeirinhos para construção de barragem (Aroeiras); poluição de rio, lixo e desrespeito à cultura dos índios 
Potiguara (Rio Tinto), carcinocultura versus pescadores e indígenas (Santa Rita); e, ainda, poluição industrial de rio versus comunidade de Maguinhos (Bayeux).

Nesses conflitos, os lados opostos possuem diferentes cotas de poder e influência, o que incide diretamente na resolução ou perpetuação do conflito. Ainda de acordo com Little (2001), existem três tipos de conflitos socioambientais, com suas respectivas dimensões: conflitos em torno do controle dos recursos naturais (dimensões políticas, sociais e jurídicas); conflitos em torno dos impactos ambientais (contaminação do meio, degradação dos ecossistemas e esgotamento dos recursos naturais); e conflitos em torno do uso dos conhecimentos ambientais (entre grupos sociais em torno da percepção de risco, como também em se tratando de lugares sagrados).

Para Alier (2007), as estruturas sociais e a utilização do meio ambiente estão entrelaçadas de muitas maneiras. Nesse sentido, é a caracterização da forma de utilização do meio que vai diferenciar os lados do conflito, evidenciar seus interesses e estabelecer um campo de tensão. Aqui cabe ressaltar que, ainda segundo Alier (2007), solucionar o conflito não equivale necessariamente à solução do problema. "Exemplificando, um conflito internacional sobre direitos de pesca pode ser resolvido com a ampliação das cotas de pescado, agudizando ainda mais o problema da sobrepesca" (ALIER, 2007, p. 107).

Os conflitos não possuem dinâmica única. Eles são históricos (ALONSO e COSTA, 2000, p.10), mudam com o tempo, se reorganizam e o poder, assim como a influência, pode ser momentâneo para uns atores. Em outros momentos, aqueles que não tinham influência alguma ou pouca influência podem, por meio de estratégia, conhecimento e outras formas, adquirir um melhor posicionamento na situação e conseguir impor sua vontade, satisfazendo seus interesses por um período de tempo. No entanto, mais à frente, tudo pode mudar novamente.

Na lógica de Lukes (1980), existem conflitos abertos, que se manifestam claramente, assim como, os latentes e os encobertos. Os latentes são aqueles que podem se manifestar quando os atores perceberem que seus interesses podem ser ou estão sendo desconsiderados em uma situação já existente. Já os conflitos encobertos são aqueles que não possuem força o suficiente para manifestar-se, mas eles são intrínsecos, eles estão ali dentro, nos bastidores (COHEN, 1981) das situações sociais. Podemos até não diferenciá-los, porque são muito parecidos. No entanto, entendemos que os primeiros, os latentes, são o estado em que se encontram os conflitos enquanto os segundos são tipos de conflitos.

Leff (2008, p.348) afirma que novos atores têm vindo à cena política fazendo novas reivindicações de melhoria da qualidade do ambiente e da vida, como também espaços de autonomia cultural e autogestão produtiva.

Muitos conflitos entendidos como territoriais se enquadram nos conflitos ambientais, pois envolvem disputas por território, em que, de um lado, estão os grandes proprietários e, de outro, agricultores, índios, ribeirinhos, etc. Assim tem ocorrido com comunidades indígenas em Rio Tinto, que lutam contra o capital sucroalcooleiro, tentando manter sua identidade enquanto têm seu espaço tomado (SILVA e LIMA, 2010). Da mesma forma acontece quando o Estado não se faz presente em situações de tomada de terras para a formação de assentamento: disputas pela exploração e utilização dos recursos em assentamentos na região semiárida da Paraíba (CUNHA e NUNES, 2008).

Sendo assim, quando falamos em conflito socioambiental, faz-se necessário compreender a sua dimensão e complexidade: além de uma série de atores envolvidos, existem as cotas de poder e influência, as articulações, as tensões, o campo do conflito em si, seus desdobramentos e suas limitações.

Nessa perspectiva, este trabalho se propôs a analisar o conflito socioambiental gerado a partir da poluição industrial da Bacia do Rio GramameMumbaba, em João Pessoa-PB, sob o enfoque dos atores envolvidos.

Desde a década de 1980, estudos vêm sendo realizados tendo como foco a Bacia do Rio Gramame. São análises das condições físico-químicas do rio 
Gramame (DA PAZ, 1988), da gestão de recursos hídricos (ROSA, 2001), do uso de agrotóxicos nas áreas irrigadas da bacia (GADELHA et al., 2001), da presença de chumbo em relação à saúde dos ribeirinhos (MACHADO, 2003), da qualidade da água (ABRAHÃO, 2006), da salubridade ambiental das comunidades (SILVA, 2006), dos efeitos do turismo na demanda de água da bacia (FONSECA, 2008), da biodiversidade, uso e conservação (BARBOSA et al., 2009) e dos impactos sobre as comunidades ribeirinhas (GARCIA et al., 2009). Para além desses, existiu um projeto no Centro de Tecnologia da Universidade Federal da Paraíba - UFPB/CNPq que tratou da restauração das nascentes e da rede de trabalho da restauração do rio Gramame, que buscou desenvolver conhecimentos voltados para a criação e atuação de uma rede de relacionamentos destinada à restauração do alto curso do rio Gramame. No Departamento de Sistemática e Ecologia-DSE/UFPB também foi desenvolvido um projeto sobre a percepção da população e a catalogação da ictiofauna e os processos de bioacumulação nos peixes.

Por outro lado, até então, não há trabalhos que tratem a situação de poluição industrial da bacia como um conflito socioambiental, especificando a comunidade de Mumbaba. Por isso, este estudo teve como objetivos a análise da dinâmica do conflito estabelecido, buscando compreender as suas origens, relações, forças e distribuição de poder entre os diversos atores, portanto, sua complexidade.

Os stakeholders da pesquisa foram os principais atores envolvidos no conflito socioambiental de poluição industrial em Mumbaba. Importa ressaltar que o conflito de poluição atinge todo o baixo Gramame. No entanto, neste trabalho tratamos apenas do conflito na Comunidade de Mumbaba, tendo em vista o fato de a comunidade integrar a região do conflito, mas foi excluída do monitoramento realizado em 2008, quando foi firmado um Termo deAjustamento de Conduta entre três indústrias do Distrito Industrial, órgãos licenciadores e fiscalizadores ambientais, Ministério Público Federal e Estadual e as comunidades de Engenho Velho, Mituaçu e Gramame.

\section{Material e mÉtodos}

Os participantes-colaboradores deste trabalho foram o Ministério Público Federal e Estadual, a ONG Associação Paraibana dos Amigos da Natureza APAN, o Comitê de Bacia Hidrográfica do Litoral Sul, a Agência Executiva de Gestão de Águas do Estado da Paraíba - AESA e a comunidade de Mumbaba, perfazendo um total de 25 entrevistados, excetuandose as conversas informais durante a realização de todo trabalho de campo.

Para análise e compreensão dos atores nos baseamos nas representações sociais sobre os problemas ambientais, técnica também utilizada por Guivant (2005), ou seja, como esses problemas são definidos e quais significados eles recebem dos diversos grupos de atores ou, ainda, como os problemas são percebidos por meio de demandas construídas socialmente, aplicamos questionários semiestruturados com os principais atores do conflito. Nesses questionários, perguntamos sobre a atuação no conflito, as parcerias existentes, o conhecimento da situação atual, as formas de resolução do problema de poluição, sobre gestão compartilhada dentre outras. Além disso, foram feitos registros visuais (fotografias e vídeos) no campo.

Os que demonstraram dispor de mais tempo e maior interesse em colaborar foram entrevistados e, posteriormente as entrevistas foram transcritas. Procedemos ainda com uma pesquisa bibliográfica e documental.

Utilizamos a técnica da Observação Participante (WHYTE, 1980), respeitando a todas as regras do campo (solicitar permissão para a realização da entrevista; marcar horários conforme disponibilidade dos pesquisados; não intervir nas situações de campo e outras), através das quais pudemos coletar grande parte dos dados.

Para a identificação dos principais atores nos apoiamos na técnica "bola de neve" (BIERNACK e WALDORF, 1981), que consiste na abordagem de atores-chave, que vão indicando outros atores a serem entrevistados. Nas situações em que não foi possível entrevistar ou aplicar questionário com o ator, buscou- 
se dados por meio de pesquisa documental e bibliográfica, pois como menciona Lodi (1986, p.14), as entrevistas, sozinhas, não são capazes de dar conta do campo, sendo necessárias a pesquisa documental e a observação.

A análise da percepção dos atores, também usada por Guivant (2005), foi realizada através das representações sociais, como também nas ideias de Tuan (1980), quando associa o termo "topofilia" ao sentimento de lugar, de pertencimento que os atores dão às sensações de estéticas, táteis, simbólicas ao relacionar-se com o meio no qual estão inseridos.

\section{A Bacia do Rio Gramame-Mumbaba}

A Bacia do rio Gramame localiza-se entre as latitudes $7^{\circ} 11^{\prime}$ e $7^{\circ} 23^{\prime}$ Sul e as longitudes $34^{\circ} 48^{\prime} \mathrm{e}$ $35^{\circ} 10^{\prime}$ Oeste, na região litorânea, em João Pessoa. Abrange os municípios de Alhandra, Conde, Cruz do Espírito Santo, João Pessoa, Pedras de Fogo, Santa Rita e São Miguel de Taipu (MACHADO, 2003). A bacia abastece $70 \%$ da Grande João Pessoa (quase 1 milhão de pessoas), através da barragem GramameMamuaba, com capacidade para 56,4 milhões $\mathrm{m}^{3} \mathrm{e}$ área de $589,1 \mathrm{~km}^{2}$. As nascentes, difusas e pontuais, localizam-se na área rural do município de Pedras de Fogo, se estendendo até praia de Barra de Gramame, limite entre os municípios de João Pessoa e Conde.

As comunidades localizadas no território da bacia apresentam problemas comuns às comunidades localizadas em periferias dos centros urbanos, como: desemprego, baixa escolaridade da população, deficiência de transportes, vias de acesso sem pavimentação, falta de água encanada, falta de escolas de Ensino Médio e Supletivo, crescente marginalização e êxodo dos jovens e adolescentes para os grandes centros por falta de opções de trabalho, estudos e lazer (GARCIA et al., 2009).

Faz parte desse contexto a Comunidade de Mumbaba, contemplada pela Agenda 21 e integrante da região do programa Cinturão Verde. A comunidade localiza-se na região sudoeste da cidade de João Pessoa e possui uma população estimada em 1.641 indivíduos de 471 famílias, de acordo com informações cedidas no Programa de Saúde da Família da comunidade.

A situação de poluição na Bacia do Rio GramameMumbaba existe desde a instalação do Distrito Industrial de João Pessoa, no final da década de 1960. Desde então, o ecossistema e os comunitários têm sofrido com os efeitos da poluição causada pelo lançamento dos dejetos das empresas nas redes de drenagem que, por sua vez, chegam aos cursos de água da bacia. O distrito localiza-se às margens da BR 101, à distância aproximada de 6 quilômetros do centro da cidade de João Pessoa. Ocupa uma área de 642 ha, sendo esta a principal fonte poluidora da bacia, contribuindo para a perda da capacidade de autodepuração dos rios Gramame, Mumbaba e Mamuaba (ABRAHÃO, 2006).

Como a área do distrito é cortada pelo riacho Mussuré, desde o início das atividades no local, ele funciona como depositário dos efluentes líquidos ali gerados. Cada indústria deveria ser responsável pelo tratamento adequado de seus efluentes e rejeitos. No entanto, os efluentes são descartados no riacho Mussuré, com ou sem tratamento, ou através de rede de drenagem pluvial existente (ABRAHÃO, 2006). 

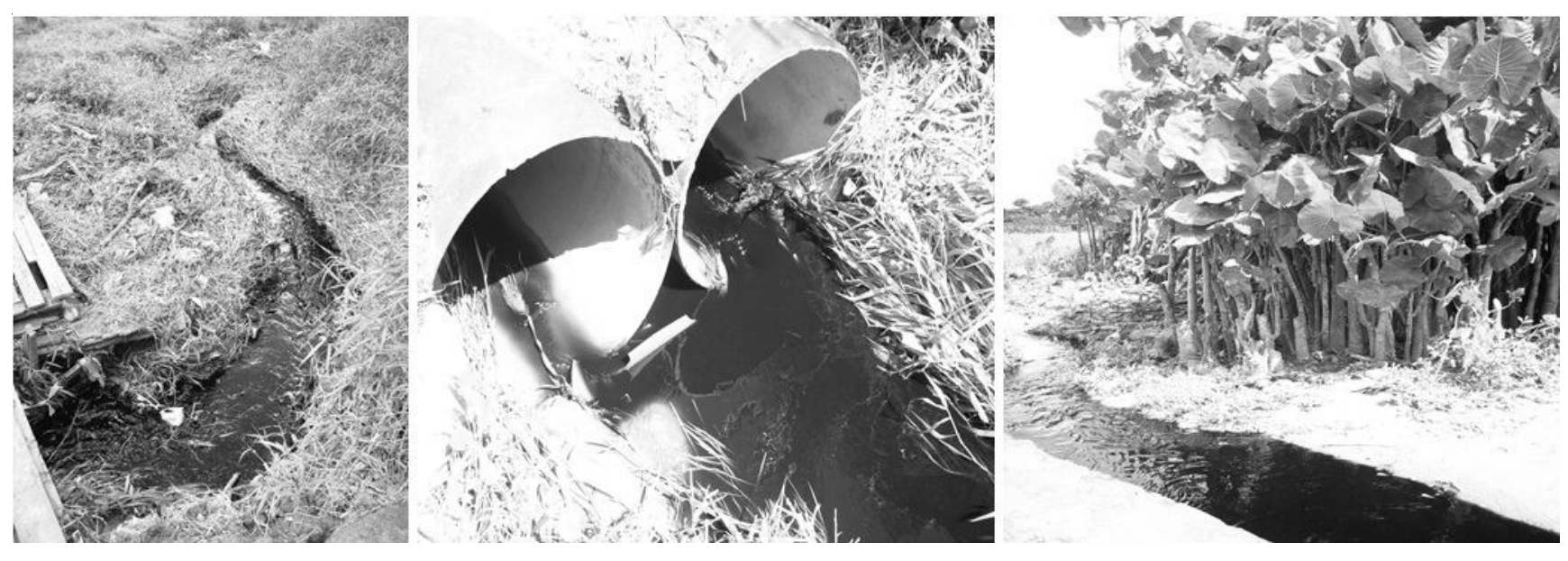

Foto 1: Efluentes industriais pela rede de drenagem e aningas, em Mumbaba.

Fonte: Arquivo pessoal-pesquisa de campo, 2011.

Na Bacia do Rio Gramame, encontram-se instaladas indústrias tradicionais, como as de produtos alimentícios, construção civil, serviços de reparação, manutenção e instalação, minerais não metálicos, metalúrgica, têxteis, etc. A maioria não conta com tratamento adequado e eficiente dos seus efluentes, tampouco têm informações detalhadas sobre as características deles, nem do destino final. Isso ocorre, sobretudo, nas unidades de pequeno porte, que evitam onerar o custo final do produto (MACHADO, 2003).

O problema de poluição industrial surge então com o funcionamento do distrito. Já o conflito tornou-se público com ações políticas que visionaram a preservação ambiental do rio Gramame, ocorridas a partir de 1984, por meio de denúncias públicas sobre o agravamento da situação (O NORTE, 1984).

Em 1992, foi criado o movimento Salve o Rio Gramame, a partir de discussões das associações comunitárias em conjunto com ambientalistas (CORREIO DAPARAÍBA, 1993).

Em 2009, foi formado um grupo ("força-tarefa"), composto por técnicos do Ministério Público em conjunto com a Superintendência de Desenvolvimento do Meio Ambiente - SUDEMA e a AESA, para realizar novas vistorias e autuações nas indústrias do distrito. Após o término dessa fase, pretende-se convocar um novo grupo de empresas para a firmação de um novo Termo de Ajustamento de Conduta - TAC, com previsão de dois anos. O novo acordo terá uma abrangência maior, envolvendo mais empresas e outras comunidades pertencentes à área do conflito.

Até então, a comunidade de Mumbaba não foi inserida nesse contexto, mesmo tendo sido o palco da morte, em 2000, de uma senhora que caiu no córrego por onde passaram, naquele momento, efluentes químicos industriais. O córrego atravessa toda comunidade e, na verdade, constitui uma rede de drenagempluvial utilizada pelas indústrias para transportar seus efluentes para a depuração nos rios da região.

\section{Resultados E Discussão}

Existem 117 empreendimentos industriais cadastrados como usuários da Bacia do Rio Gramame. Das outorgas concedidas pelo órgão licenciador, a apenas uma delas é permitindo o lançamento de efluentes no rio Mumbaba, muito embora ela se encontre após a comunidade, não tendo relação alguma com o córrego que atravessa a comunidade de Mumbaba. Isso nos mostra que todos os outros lançamentos realizados são feitos de forma irregular.

Percebeu-se que muitas dessas indústrias estão com processo de licença e outorga ainda em andamento, mas que já descarregam seus poluentes nos corpos d'água da região. Esses poluentes são considerados 
perigosos, tanto para a população humana como para o ecossistema em geral. No entanto, as indústrias, na maioria das vezes, não se enxergam como poluidoras, porque afirmam que seus efluentes são tratados. Essas indústrias já foram representadas por alguns de seus funcionários em reuniões que ocorreram em Mumbaba, mas até então não lograram êxito no que tange à resolução do problema e do conflito.

O Ministério Público, entendido como mediador do conflito, realizou vistorias no Distrito Industrial e está em busca da firmação de um novo TAC. No entanto, seu trabalho, apesar de representar um exemplo de mediação para o país, caminha a passos lentos, sobretudo por causa da morosidade dos processos, mas também pela ausência de articulação entre todos os atores do conflito.
A SUDEMA e a AESA, como órgãos estatais licenciadores e fiscalizadores, não desconhecem a situação de conflito, mas também não possuem atuação nenhuma sobre o mesmo, muito embora nos regramentos que fundamentam a existência desses órgãos haja a atribuição de arbitragem dos conflitos relacionados à água. No que tange à articulação, o contato com os demais atores é restrito, mesmo a AESA sendo o órgão que coordena o Comitê de Bacia Hidrográfica do Rio Gramame e Abiaí.

No passado, a APAN já teve atuação no conflito. Atualmente, nos foi informado que há interesse e que, inclusive, a ONG participou da formatação do atual comitê de bacia. No entanto, sua representante afirmou que a ONG foi excluída ao tentar participar como titular do órgão colegiado de gestão da bacia.

\begin{tabular}{|c|l|}
\hline Classificação & \multicolumn{1}{c|}{ Ator Social } \\
\hline Privado & \multicolumn{1}{c|}{ Indústrias } \\
\hline Estado & \multicolumn{1}{|c|}{ Ministério Público } \\
\cline { 2 - 2 } & $\begin{array}{l}\text { SUDEMA - Superintendência de Administração do Meio } \\
\text { Ambiente }\end{array}$ \\
\cline { 2 - 2 } & $\begin{array}{l}\text { AESA - Agência Executiva de Gestão de Águas do Estado } \\
\text { da Paraîba }\end{array}$ \\
\hline Terceiro Setor & APAN - Associação Paraibana dos Amigos da Natureza \\
\hline Órgão Colegiado & \multicolumn{1}{|c|}{ Comitê de Bacia do Litoral Sul } \\
\hline Comunidade & \multicolumn{1}{|c|}{ Comunitários } \\
\hline
\end{tabular}

Quadro 1 - Identificando os atores.

Fonte: Dados de pesquisa.

O comitê, coordenado pela AESA, está ainda em sua segunda gestão. Portanto, ainda em processo de formação. Não existe atuação no conflito, mesmo tendo como uma de suas atribuições a arbitragem de conflitos. Com os outros atores, não há articulação, mas também reconhecem a existência do conflito gerado a partir da poluição industrial.

Os comunitários entrevistados moram há pelo menos dez anos no local. Todos afirmaram que a situação já se prolonga há anos e tende a piorar. Eles declararam que os efluentes têm gerado problemas na saúde da população, sobretudo na das crianças. Alguns deles reconhecemque o lugar é impróprio para morar devido à poluição, não apenas manifestada por meio dos efluentes, mas também poluição atmosférica, que agrava a situação.

No passado, os comunitários usaram o ecossistema para pesca, banho entre outros usos. Atualmente, ainda existe uso dos corpos hídricos da região, muito embora seja de conhecimento de todos a situação de poluição. Além disso, os comunitários também contribuem para a situação de poluição, por meio do descarte indiscriminado de lixo doméstico por toda a comunidade (ALIER, 2007). 

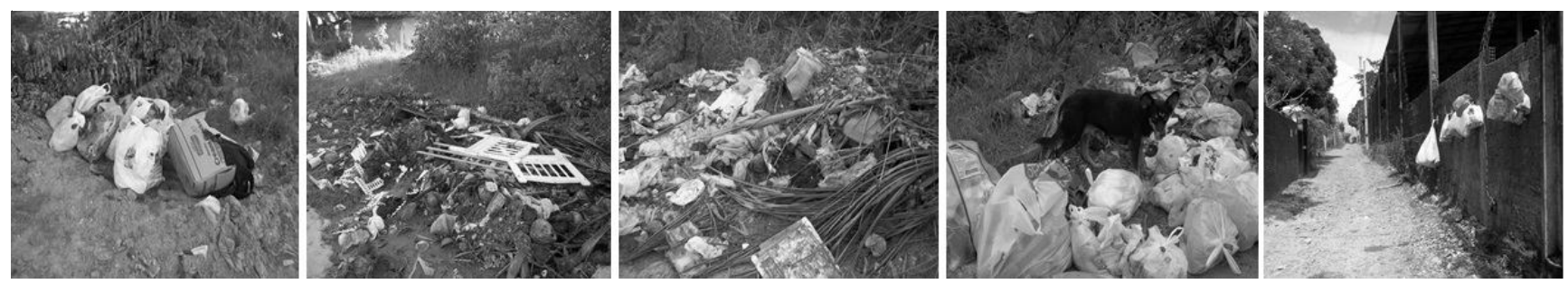

Foto 2 - Lixo doméstico em toda comunidade de Mumbaba.

Fonte: Arquivo pessoal-pesquisa de campo, 2011.

Quanto à articulação e participação em busca da resolução do problema e do conflito, o que pudemos perceber é que não existem. Existiram tentativas de articulação interna, mas são sempre atrapalhadas por membros internos da comunidade, cooptados pelas próprias indústrias que oferecem empregos em troca de, por exemplo, avisarem quando chega fiscalização no território da comunidade.

Constatamos que, para além da situação de poluição, o problema e o conflito giram também em torno do território onde a comunidade se instalou. Trata-se de uma zona industrial. Enquanto os comunitários afirmam que já habitavam a área ou que, posteriormente, receberam os terrenos das indústrias, estas, por outro lado, afirmam que eles são "invasores".

Dessa forma, à comunidade, além de saneamento, infraestrutura, faltam ações de sensibilização ambiental, eficazes o suficiente para despertá-los para as formas corretas de disposição dos resíduos sólidos e líquidos domésticos. Que não simplesmente joguem nas ruas ou no próprio córrego, como é muito comum. Quem não mora próximo ao córrego, ou seja, quem não é afetado por ele, não abraça a causa. Tem-se a impressão de que a população já não mais se incomoda com aquele cenário. Parece ainda que não há identificação da população com os rios da região, pois o meio ambiente não se apresenta como questão relevante para as classes sociais que ainda não têm asseguradas as condições básicas de sobrevivência (FUKS,1998).

No que tange ao Distrito Industrial de João Pessoa, é improvável que todas as indústrias fechem com as autuações do Ministério Público e parceiros. Os rios não serão desviados e os moradores provavelmente não serão deslocados do lugar. Permanece o jogo de poder e influência, onde, como bem descreveram os comunitários, muito embora não tendo a ideia das forças e influências que não se apresentam claramente, o "dinheiro tem ainda tem conseguido se sobressair".

Os papéis da agência de água, do órgão que administra o meio ambiente estadual e do comitê, são imprescindíveis na luta contra a poluição industrial da bacia como um todo, porém, no conflito, que é apenas um dentre tantos, segundo o presidente do comitê, esses atores são coadjuvantes, com pouca ou nenhuma influência para a resolução do problema.

Quanto aos regramentos, é inegável que houve um desenvolvimento em termos de abrangência da lei, mas o problema é sua aplicabilidade. O processo de descentralização das responsabilidades, culpabilização e estabelecimento de conceitos claros - como o de poluição - fizeram com que os recursos hídricos ficassem resguardados apenas teoricamente e, portanto, com menor possibilidade de atenderem às presentes $\mathrm{e}$ futuras gerações.

O papel dos atores sociais, seja dos órgãos estabelecidos pelas políticas nacionais, estaduais e municipais de meio ambiente e recursos hídricos, ou até mesmo das organizações do terceiro setor que trabalhem com a temática, é assegurar o equilíbrio dos recursos, dos usos e intermediar os possíveis conflitos em meio a um cenário de tensão social, política e ambiental entre o progresso econômico, a preservação e a sustentabilidade socioambiental. Para tanto, mesmo com o aparato jurídico ambiental, os desafios são imensos, pois vai além de uma questão de 
sensibilização, onde o capital natural, antes de ser visto como tal, é um sistema que possui leis e funcionamento próprios.

Nesse sentido, entende-se que não há a articulação devida para que o problema e/ou o conflito sejam resolvidos e, enquanto isso, os regramentos, as funções, os papéis e o poder e influência conferidos a cada indivíduo e órgão ficam perdidos, inoperantes em meio a um clima tenso e degradante. Trata-se de uma questão ética, trata-se da busca pela justiça ambiental.

As perspectivas de resolução do conflito deste estudo passam integralmente pela gestão de recursos hídricos da Bacia do Rio Gramame-Mumbaba e, para isso, é necessária, além da obediência aos regramentos federais, estaduais e municipais, a participação de todos os atores direta ou indiretamente ligados à causa. Incluem-se aí a agência de águas, o órgão licenciador e o comitê de bacia, que tem se mostrado ausente na gestão porque ainda é um órgão embrionário.

Alguns conceitos, como o de participação, articulação, mobilização e mediação, também são imprescindíveis não apenas à compreensão da situação de conflito, mas à resolução das situações problemáticas. No caso da mediação na situação do conflito de Mumbaba, o que se pode dizer é que, se falta credibilidade por parte da comunidade, é porque não existe informação, não existe conexão entre estes e o Ministério Público, por exemplo, fato muito comum, como temos visto.

Para obtermos a melhor solução, tanto para o problema como para o conflito, é necessário um exercício de separação das partes, decomposição e, posteriormente união, associação, relação entre elas. A partir desse exercício de simplificação e complexificação, por meio da reordenação das partes, é que se pode proceder a uma análise do objeto estudado. Compreendemos que, só com o atendimento das questões de cada esfera (ambiental, social, política/administrativa, jurídica, técnica e econômica), a situação poderá melhorar para todas as partes, sobretudo para o meio e para as pessoas que ali habitam. Assim como no estudo de Silva e Lima (2010), é possível observar a contradição no modo de uso e exploração dos recursos. Enquanto as indústrias utilizam os recursos hídricos para captação de água, assim como "depósitos", a população, embora aja também de forma inadequada em alguns aspectos como vimos, utiliza os recursos em prol da coletividade.

Quanto às medidas/procedimentos de resolução da situação declarados pelos agentes deste estudo, afirmamos que algumas delas são ingênuas, outras tecnicistas ou simplistas porque atendem a interesses individuais, pontuais. Nesse sentido, propomos alguns caminhos que podem ser seguidos pelos tomadores de decisão para que não apenas o problema seja resolvido, mas o conflito. Esta é uma questão em que temos insistido, mas, que caso não seja atendida, o conflito e/ou o problema podem ser sanados momentaneamente, mas permanecerão existindo até que aconteça um novo fenômeno que o faça emergir novamente.

As questões indicadas abordam desde as atitudes relacionadas às origens do conflito até medidas de compensação, reparação e incentivo. Além disso, o poder público, em todas as suas esferas, deve entrar efetivamente em Mumbaba, realizando obras de infraestrutura, por exemplo.

Também em Cunha e Nunes (2008) é demonstrada a necessidade de uma reorganização dos direitos de propriedade e constituição de arranjos sociais para o efetivo controle dos recursos comuns (naquele caso, da terra). Enxergamos a mesma necessidade no caso em questão, onde só depois dessa reorganização, tendo por base a justiça ambiental e a aplicação efetiva da legislação, é que se pode pensar em resolução do conflito e do problema.

Além de medidas de nível micro, mas que resultam em efeitos positivos, propomos mudanças nas estruturas dos empreendimentos industriais, assim como aplicabilidade dos instrumentos de planejamento e gestão dos recursos hídricos.

Todos esses esforços para a resolução serão perdidos se não houver a união das forças estatais, comunitárias, privadas e do terceiro setor, onde cada qual cumpra com aquilo que se propôs.

O fluxo de informações, assim como o 
monitoramento e controle de todos sobre todos, tambémé fundamental para o encaminhamento devido. Não é apenas com o cumprimento dos princípios do usuário-pagador e do poluidor-pagador que o problema será resolvido.

Todas as indústrias devem ser monitoradas, fiscalizadas (o que está em processo) e todas devem rever seu processo produtivo, com ênfase no destino que dão aos seus resíduos, partículas, gases e efluentes. Estes devem ser tratados ou filtrados.

A população deve ser esclarecida e atualizada (os comunitários devem se mobilizar, inclusive para obter estas informações) sobre a situação, que deve ser comprovada por testes/análises. Além disso, são necessárias a revitalização do córrego e a construção de passarelas nos pontos críticos. É necessária, portanto, a articulação entre os atores, o cumprimento de suas funções e o atendimento à legislação vigente, o que não tem ocorrido desde o estabelecimento do conflito. Só assim aquela paisagem verde rural e aqueles que ali habitam poderão reencontrar o equilíbrio de outrora.

Este não pode ser mais um conflito rejeitado, velado, encoberto. Deve-se rejeitar a ocultação da realidade, a fim de evitar a entrada ou a manifestação do conflito. Negar a existência do conflito ou rejeitá-lo só prejudicará as partes envolvidas, sobretudo as mais vulneráveis, desprovidas ou com pouco poder e influência. Esperamos que, no fim das contas, os reais interesses dos agentes envolvidos e, mais importante que isso, suas ações, sejam diretamente proporcionais às possibilidades de se atingir um denominador comum, por meio de cenários economicamente viáveis, socialmente justos, ambientalmente sustentáveis e politicamente democráticos.

Dessa forma, o conflito de poluição industrial da Bacia do Rio Gramame configura-se como um conflito ambiental territorial (ZHOURI e LASCHEFSKI, 2005), visto que se liga às formas de apropriação material do espaço, onde, por um lado, a população deseja condições salubres em seu espaço de moradia, enquanto as indústrias querem o espaço para lançar seus efluentes. Por isso, as origens do conflito estão relacionadas ao fato de os comunitários serem vistos como invasores daquela área. $\mathrm{O}$ córrego é o meio através do qual o conflito se manifesta e por meio do qual as indústrias impõem seu poder, sua influência, sua afirmação de que ali é o lugar delas e não dos comunitários. Sendo assim, o foco do conflito não é a poluição dos rios nem as acusações de invasão, mas a rede de drenagem de água pluvial transformada em duto para o transporte de efluentes. Esta que se transformou em sinônimo de riscos de saúde à comunidade e ao ecossistema.

\section{Agradecimentos}

Agradecemos o apoio do Conselho Nacional de Desenvolvimento Científico e Tecnológico-CNPq. Agradecemos ainda ao PRODEMA-UFPB, assim como a todos os comunitários e demais atores que colaboraram com o desenvolvimento da pesquisa.

\section{REFERÊNCIAS}

ABRAHÃO, Rafael. Impactos do lançamento de Efluentes na Qualidade da Água do Riacho Mussuré. 2006. 140 f. Mestrado. Dissertação do Programa de Pós-Graduação em Desenvolvimento e Meio Ambiente. Universidade Federal da Paraíba, João Pessoa, 2006.

ACSELRAD, Henri; MELLO, Cecília C. do Amaral; BEZERRA, Gustavo das Neves. O que é Justiça Ambiental. Rio de Janeiro: Garamond, 2009.

ALIER, Juan Martínez. O Ecologismo dos Pobres: conflitos ambientais e linguagens de valoração. Maurício Waldman (Trad.). São Paulo: Contexto, 2007.

ALONSO, Angela; COSTA, Valeriano. Por uma Sociologia dos conflitos ambientais no Brasil. Centro de Estudos da Metrópole. Conflitos Urbanos e Associativismo. 2000. Disponível em: <http:// www.centrodametropole.org.br/pdf/Angela.pdf $>$. 
Acesso em: 02. nov. 2011.

BARBOSA, José Etham de Lucena; WATANABE, Takako; DA PAZ, Ronilson (Orgs). A Bacia do Rio Gramame: Biodiversidade, uso e conservação. Campina Grande: EDUEPB, 2009.

BECK, Ulrich. Environment Risks and Public Perceptions. In: BERGHAHN JOURNALS. Environment and Society. London, 2007. P. 15-28.

BIERNACK, P.; WALDORF, D. Snowball Sampling. Sociological Methods and. Research, 1981.

COHEN, Harry. Connections: understanding social relationship. Ames: The Lowa University Press. 1981.

\section{CORREIO DA PARAÍBA. Organismos discutem} a sujeira no Rio Gramame. João Pessoa-PB: Fevereiro, 1993. [S.d].

CUNHA, Luis Henrique; NUNES, Aldo Manoel Branquinho. Proteção da natureza e conflitos ambientais em assentamentos rurais. Desenvolvimento e Meio Ambiente. N.18. p.27-38. Jul-dez 2008. Anais. Editora UFPR. Disponível em: $\langle\mathrm{http}: / /$ migre.me/dvPkN $>$. Acesso em: 05. out. 2011.

DAPAZ, Ronilson José. Estudo das Condições físico-químicas do Rio Gramame, Conde, Paraíba, Brasil. 1988. 48 f. Graduação em Ciências Biológicas. Universidade Federal da Paraíba, João Pessoa, 1988. Disponível em: <http:// www.ronilson-paz.net/download/pdf/paz1988.pdf>. Acesso em: 08. Jul.2011.

FONSECA, Francisco. Efeitos do Turismo na demanda d'água da Bacia do Rio Gramame: Estudo de Caso. 2008. 143 f. Mestrado. Dissertação do Programa de Pós-graduação em
Engenharia Civil e Ambiental. Universidade Federal de campina Grande, Campina Grande, 2008.

FUKS, Mario. Arenas de Ação e Debate Públicos: conflitos ambientais e a emergência do meio ambiente enquanto problema social no Rio de Janeiro. Dados. Revista de Ciências Sociais. V.41.N.1. Rio de Janeiro, 1998. Disponível em: $<$ http://www.scielo.br/scielo.php?pid=S0011$52581998000100003 \&$ script $=$ sci_arttext $>$. Acesso em: 10.ago.2011.

GADELHA, Carmem Lúcia Moreira et al. O uso de agrotóxicos nas áreas irrigadas da Bacia do Rio Gramame no Estado da Paraíba. In: $21^{\circ}$ Congresso Brasileiro de Engenharia Sanitária e Ambiental. 2001. João Pessoa. Anais. Disponível em: <http:// www.bvsde.paho.org/bvsaidis/brasil21/vi-083.pdf $>$. Acesso em: 08 jul. 2011.

GARCIA, Loreley Gomes; NUNES, Edilon Mendes; CORDEIRO, Ana Maria R.; MONTEIRO, Lorena Lúcia. Relatório Socioambiental do impacto da contaminação do rio Gramame pelas indústrias sobre as comunidades de Gramame, Engenho Velho e Mituaçu. mar. 2009. 50 p.

GUIVANT, Julia S. Mapeando os caminhos da Sociologia Ambiental. In Política e Sociedade. Revista de Sociologia Política. V.4. N. 7. out. 2005. P.9-26.

\section{LEFF, Henrique. Saber Ambiental:}

Sustentabilidade, Racionalidade, Complexidade, Poder. Lúcia Mathilde Endlich Orth (Trad.). 6. ed. Petrópolis, RJ: Vozes, 2008. 344 p.

LITTLE, Paul E. Os conflitos Socioambientais: um campo de estudo e de ação política. In: BURSZTYN, Marcell (Org). Adifícil sustentabilidade: política energética e conflitos ambientais. Rio de Janeiro: Garamond, 2001. P. 
107-123.

LODI, João Bosco. A entrevista: teoria e prática.

5. ed. São Paulo: Pioneira, 1986. 176 p.

LOPES, José Sérgio Leite. Sobre processos de

"Ambientalização" dos conflitos e sobre dilemas da participação. In Horizontes Antropológicos. Ano

12. N. 25. P.31-64. Porto Alegre, 2006. Disponível em: <http://www.scielo.br/pdf/ha/v12n25/

a03v1225.pdf $>$. Acesso em: 12. set. 2011. Acesso

em: 10. Set. 2011.

LUKES, S. Poder: uma visão radical. Brasília:

Editora UNB: 1980. P.7-57.

MAPA DA INJUSTIÇAAMBIENTAL E SAÚDE NO BRASIL. 2010. Disponível em: <http://

www.conflitoambiental.icict.fiocruz.br/>. Acesso em: 03. mar. 2010.

MACHADO, Taysa Tâmara Viana. Investigação da Presença de Chumbo (Plumbum) na Bacia do Rio Gramame e suas Possíveis Implicações na Saúde Pública da Região. 2003. 118 f. Mestrado. Dissertação do Programa de Pós-Graduação em Desenvolvimento e Meio Ambiente. Universidade Federal da Paraíba, João Pessoa, 2003.

O NORTE. Jovani quer levar à Justiça quem polui águas do Gramame. João Pessoa-PB: Novembro, 1984. [S.d].

ROSA, Maria do Socorro Mendes. Gestão participativa e descentralizada dos recursos hídricos: uma contribuição para a Bacia do Rio Gramame, PB. 2001. 100 f. Mestrado.

Dissertação do Programa de Pós-graduação em
Desenvolvimento e Meio Ambiente. UFPB, João Pessoa, 2001.

SILVA, Marta Gomes; LIMA, Edvaldo Carlos. Conflitos Territoriais no município de Rio Tinto/PB: O caso da retomada das terras da aldeia Monte Mor. In: XVI Encontro Nacional de Geógrafos, 2010. Anais. Porto Alegre. Disponível em: <http:// migre.me/dvPnc>. Acesso em: 10. set. 2011.

SILVA, Nayra Vicente Sousa da. As condições de Salubridade Ambiental das comunidades periurbanas da bacia do rio Gramame: diagnóstico e proposição de benefícios. 2006. 122 f. Mestrado. Dissertação do Programa de Pósgraduação em Engenharia Urbana e Ambiental. Universidade Federal da Paraíba, João Pessoa, 2006.

TUAN, Y Fu. Topofilia: um estudo da percepção, atitudes e valores do meio. Bertrand, 1980. Brasil. $288 \mathrm{p}$.

WALDMAN, Maurício. Meio Ambiente \& Antropologia. São Paulo: SENAC São Paulo, 2006. 240 p.

WHYTE, Willian Foote. Treinando a Observação Participante. In ZALUAR, Alba. Desvendando as Máscaras Sociais. 2. ed. Rio de Janeiro: Francisco Alves Editora, 1980.

ZHOURI, A.; LASCHEFSKI, K.; BARROS, D. P. Introdução: desenvolvimento, sustentabilidade e conflitos socioambientais. In: ZHOURI, A.(Org.). A insustentável leveza da política ambiental: desenvolvimento e conflitos socioambientais. Belo Horizonte: Autêntica, 2005.

RECEBIDO EM 13/8/2012

ACEITO EM 9/5/2013 